\title{
VEGFR2-specific FnCAR effectively redirects the cytotoxic activity of T cells and YT NK cells
}

\author{
Sergey V. Kulemzin ${ }^{1, *}$, Andrey A. Gorchakov ${ }^{1,2, *}$, Anton N. Chikaev ${ }^{1}$, Valeriya V. \\ Kuznetsova $^{1}$, Olga Y. Volkova ${ }^{1}$, Daria A. Matvienko ${ }^{1,2}$, Alexey V. Petukhov ${ }^{3}$, Andrey \\ Y. Zaritskey ${ }^{3}$ and Alexandr V. Taranin ${ }^{1,2}$ \\ ${ }^{1}$ Institute of Molecular and Cellular Biology SB RAS, Novosibirsk, Russia \\ ${ }^{2}$ Novosibirsk State University, Novosibirsk, Russia \\ ${ }^{3}$ Institute of Hematology, Almazov National Medical Research Centre, St Petersburg, Russia \\ *These authors contributed equally to this work \\ Correspondence to: Alexandr V. Taranin, email: taranin@mcb.nsc.ru
}

Keywords: chimeric antigen receptors; NK cells; Fn3; VEGFR2; FnCAR

Received: March 06, $2017 \quad$ Accepted: January 02, $2018 \quad$ Published: January 09, 2018

Copyright: Kulemzin et al. This is an open-access article distributed under the terms of the Creative Commons Attribution License 3.0 (CC BY 3.0), which permits unrestricted use, distribution, and reproduction in any medium, provided the original author and source are credited.

\section{ABSTRACT}

T and NK cells armed with chimeric antigen receptors (CAR) are promising tools for the specific elimination of cancer cells. In most CAR designs implemented to date, the recognition of target cells is mediated by single-chain variable fragments (scFvs) derived from murine monoclonal antibodies. This format, however, has a number of limitations, including its relatively large size and potential immunogenicity in humans. In this study, we explored the feasibility of using human fibronectin type III domains (Fn3) as the antigen recognition domain in CARs. Human Fn3 domains have lower predicted immunogenicity compared to mouse-derived sequences, and a reduced molecular weight compared to scFvs. We created a functional CAR using a VEGFR2specific Fn 3 module replacing the conventional ScFv. The resulting FnCAR specifically potentiates the cytotoxic activity of human T cells and YT NK cells in the presence of VEGFR2-positive targets. These findings demonstrate that Fn3 domains can be used in CARs for antigen recognition.

\section{INTRODUCTION}

T-cells expressing CD19-specific Chimeric Antigen Receptors (CARs) demonstrated remarkable anti-tumor activity in patients with advanced B-cell malignancies [1-6], and other CARs are currently being evaluated in the clinical and preclinical settings. The antigen-recognition domains of most CARs contain $\mathrm{scFv}$ (single-chain fragment variable) sequences derived from well-characterized monoclonal antibodies specific to tumor-associated surface antigens. While the scFv-derived targeting domains inherit the specificity and versatility of monoclonal antibodies, they also have a number of important limitations. The availability of fully human scFv sequences is still scarce, and reducing the immunogenicity of murine scFvs by grafting CDRs onto human framework sequences often results in unpredictable changes in the folding or antigen recognition capacity of the resulting scFvs. Furthermore, the correct folding of an $\mathrm{scFv}$ requires the proper formation of intramolecular disulfide bonds that may complicate the design of multispecific CARs incorporating two or more scFvs. Finally, the framework regions of scFvs have been shown to frequently produce CARs that are prone to tonic signaling - an unwanted effect that results in the premature exhaustion of CAR T-cells [7].

The 10th type III domain of human fibronectin 1 (Fn3) is a small globular module comprising seven antiparallel beta-strands folded as two beta-sheets [8]. Surface-exposed loops connecting these beta-strands generally have little influence on the structural stability of the Fn3s and, therefore, their randomization can be used to obtain Fn3 proteins of the desired binding specificity and affinity. Thus, highly complex Fn3 libraries have been created and successfully screened using phage, yeast, and 
ribosomal displays to select the specific variants capable of binding target proteins with high affinity at the picomolar to low nanomolar range [9-11]. Of these, CD20-, CEA-, EGFR-, IGF-1R, and VEGFR2-specific Fn3s have been validated in pre-clinical and clinical settings as promising imaging and/or therapeutic molecules [12-15]. While Fn3s are structurally homologous to the variable fragments of antibodies, they are more compact ( $~ 94$ aa), devoid of intramolecular disulfide bonds and are naturally present as multidomain chains. In addition, several engineered Fn3s were found to recognize concave epitopes that are typically missed by scFvs $[10,16]$. These properties make Fn3-based domains an attractive option to the standard scFv-derived modules, potentially allowing for the broadening of the repertoire of targetable epitopes and streamlining the design of multi-specific CARs.

In this proof-of-concept study, we designed and characterized a VEGFR2-specific CAR with the antigenrecognition moiety derived from the Fn3-scaffold. We show that FnCARs are functional, as they drive the specific activation of human $\mathrm{T}$ cells. In addition, the expression of these FnCARs promotes the specific cytotoxicity of primary human T cells and YT NK cells in vitro. These results support the feasibility of using Fn3 domains in CARs.

\section{RESULTS}

\section{Construction of VEGFR2-specific FnCARs}

We used a modular pCDH-based lentiviral system [17] in order to generate a series of FnCARs specific for the human VEGFR2. Antigen-recognition module of the FnCARs obtained was based on the clone K10 described previously [13] whereas IRES-linked copGFP reporter allowed convenient detection of the transduced cells. Testing several combinations of CAR modules was warranted to ensure that the FnCARs are efficiently transported to the cell surface and are easily detectable. Specifically, several FnCAR variants were constructed that differed in the signal peptides (Gaussia princeps luciferase vs. mouse Igk), position of the myc-epitope (central and/or $\mathrm{N}$-terminal), and cytoplasmic signaling sequences (CD3z vs. CD28+CD3z). All FnCARs shared the same spacer region derived from the human $\mathrm{IgG} 1$ (hinge- $\mathrm{CH} 2-\mathrm{CH} 3$ ) (Figure 1A).

\section{FnCARs are expressed on the surface of Jurkat cells}

First, we verified the specificity of the VEGFR2specific Fn3 used. This Fn3 was produced in recombinant form in $E$. coli as a fusion with 2xStrep-2xFLAG-6xHis tag and used for staining 293T cells designed to stably express VEGFR2 (Supplementary Figure 1). A specific anti-FLAG signal was observed only for VEGFR2- expressing cells, but not in the isogenic negative controls (Figure 1B), which cross-validates both the Fn3(VEGFR2) and the target cells. Next, we asked whether FnCARs could be produced in a Jurkat T-cell line and, if so, whether they become surface expressed. The constructs obtained were used for producing VSV-G pseudotyped lentiviral particles that were transduced into Jurkat cells. Our Western blot and FACS data confirm that FnCARs are successfully synthesized by the transduced Jurkat cells at comparable levels (Figure 1C) and that they are indeed expressed on the cell surface, as assayed by anti-IgG1 staining (Figure 1D, shown for kVR2-28z).

\section{FnCARs can activate Jurkat $T$ cells}

Having established the specificity and surface expression of FnCARs, we proceeded to test their functionality. FnCAR-Jurkat cells display specific and rapid activation (Figure 1E) when incubated with the appropriate target cells (VEGFR2+, solid lines) but not with isogenic control cells (VEGFR2-, dashed line) as assayed by the upregulation of an early activation marker CD69. Our data thus indicate that regardless of the position of the myc epitope or the signal peptide used, FnCARs show robust activation properties in the context of Jurkat cells.

\section{FnCARs are functional in the context of primary human $T$ cells}

Although Jurkat cells are routinely used for rapid and convenient testing of different CAR designs, they are not cytotoxic. Hence, we asked whether FnCARs would be expressed by the transduced primary human $\mathrm{T}$ cells and, if so, whether this would result in their VEGFR2specific activation and cytotoxicity.

Given that all of the FnCAR designs tested hereinabove behaved very similarly, we picked a single representative second-generation FnCAR variant, kVR228z. Much as was observed for the FnCAR-Jurkat cells, transduced primary human $\mathrm{T}$ cells readily expressed kVR2-28z (Figure 2A) and became specifically activated upon co-incubation with VEGFR2+ cell targets, as manifested by the upregulated CD69+ expression (Figure 2B). Accordingly, FnCAR-T cells were moderately cytotoxic toward VEGFR+ cell targets (Figure 2C).

\section{FnCARs are functional when expressed by a human NK-cell line, YT}

Human NK cell lines (NK-92, YTS, KHYG-1, etc.) represent an attractive platform for creating allogeneic CAR-NK cell lines that can be universally administered to cancer patients in an "off-the-shelf" format without the need for patient-specific manufacture [18]. Therefore, we turned to one such NK-cell line, YT [19], which offers the advantage of easy transduction and IL2-independence, 
for exploring whether our FnCARs can endow them with VEGFR2-specific cytotoxicity.

First, we ascertained the surface expression of FnCARs by YT cells. Similarly to FnCAR-Jurkat cells, FnCAR expression was readily detectable on transduced YT cells (Figure 3A). Notably, the incorporation of a flexible linker between Fn3 and IgG1 domains resulted in a modest increase in the surface expression of FnCARs (Figure 3A). In addition, a side-by-side comparison of transduced FnCAR-YT cells stained with either myc- or IgG-specific conjugates shows that placing the myc epitope between the Fn3 and IgG1 modules was somewhat suboptimal for flow cytometry purposes: although detectable, it appeared partially shielded from the interaction with anti-myc antibodies. Instead, when the myc epitope was positioned between the signal peptide and the Fn3 module, this enabled the robust detection of the CAR (Figure 3B).
Next, we asked whether FnCAR-YT cells were cytotoxic. kVR2-28z CAR was selected to measure the FnCAR-mediated cytotoxicity of YT cells. Indeed, FnCAR-YTs killed VEGFR2-expressing HEK293T cells and spared VEGFR2-negative cells even at low E:T ratios (Figure 4A).

In order to determine whether the observed enhanced cytotoxicity of FnCAR YT cells was also accompanied with increased and specific cytokine release, we analyzed the IFNgamma secretion by FnCAR YT cells co-cultured with target (VEGFR2+) or non-target (VEGFR2-) cells. As a control, irrelevant FnCAR YT cells recognizing a distinct molecule (CEA) and CARless unmodified YT cells were included in the experiment. Much as was expected, FnCAR YT cells displayed a pronounced and specific IFNgamma release upon FnCAR engagement by cognate VEGFR2-epxressing cells (Figure 4B). Taken together, these data indicate that engineering
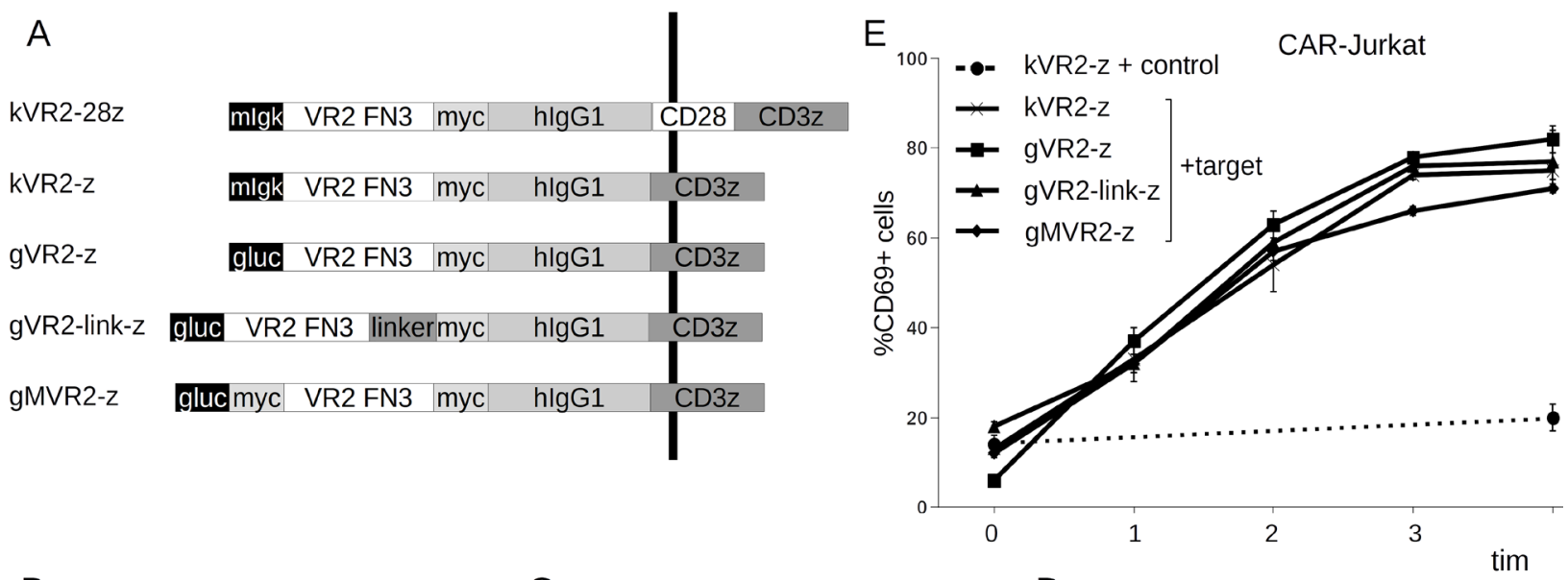

B

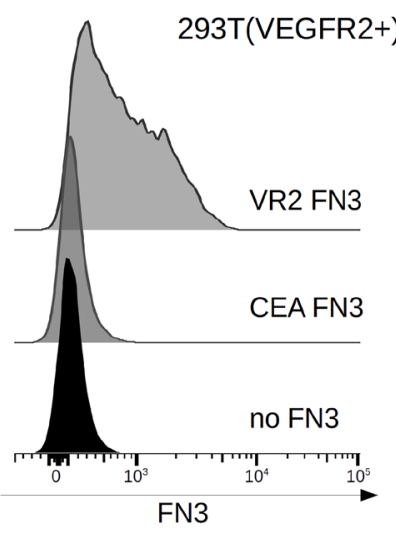

C

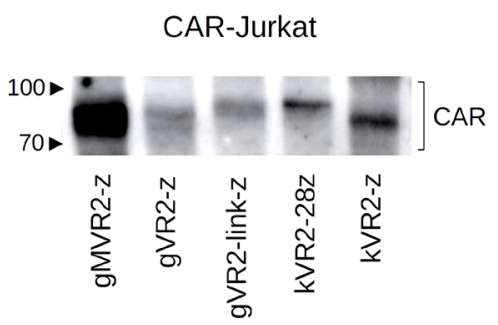

D

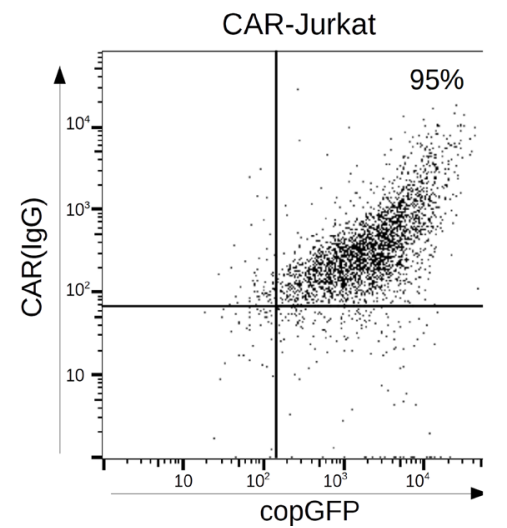

Figure 1: (A) Schematic of CAR constructs containing VEGFR2-specific Fn3-based antigen-recognition module. CARs obtained encompass leader sequences from either mIgk or Gaussia princeps luciferase (Gluc), VEGFR2-specific Fn3 sequence (VR2 FN3), myc epitope tag, hIgG1 spacer region (hinge-CH2-CH3 domains), CD28 region (transmembrane and signaling sequences), and CD3 $\zeta$ region (transmembrane and/or signaling sequences). The vertical black line denotes the cell membrane. (B) FACS detection of VEGFR2 expression on the surface of HEK293T(VEGFR2+) cells stained with either recombinant FLAG-tagged Fn(VEGFR2)_VR2 FN3, FLAG-tagged Fn3 of irrelevant specificity-CEA FN3 [15], or left unstained. (C) Western blot detection of FnCAR expression in transduced Jurkat cells (anti-myc). (D) flow cytometry surface staining of kVR2-28z FnCAR-expressing Jurkat cells (becoming copGFP+ upon transduction) with anti-hinge (IgG-specific APC-labeled) conjugates. (E) Expression of the activation marker CD69 on CAR-Jurkat cells incubated with HEK293T(VEGFR2+) target cells or isogenic control cells (HEK293T) for the times indicated. 
FnCARs into NK cells may significantly enhance their effector functions in response to the appropriate target cells, which warrants further testing of this platform in pre-clinical models.

\section{DISCUSSION}

Current progress in CAR T-cell therapies is hampered by the lack of truly cancer-specific surface markers targetable with scFv-based CARs. This technological bottleneck is partially addressed by designing different variants of "smart" CARs that are capable of discriminating combinations of antigens from single-antigen carrying cells [20-25]. In fact, CAR platform is plagued by the same issue that has been long known for monoclonal antibody-based therapies, i.e. tumor escape as a result of immunoediting. Hence, several groups have focused their efforts on the design of bi-specific CARs [26-28]. Both issues converge in the necessity of developing alternative formats of compact antigenrecognition modules that would help expand the repertoire of targetable cancer cell surface markers and would also be amenable for structure-guided multimerization. Several non-scFv formats that partially fit this description have been tested in the CAR context, which include VHHs (nanobodies) [29-32], VLRs [33], DARPins [34], and affinity peptides [35-37]. At present, neither of them has been reported to be successfully used for creating bi- or multispecific CARs. Importantly, these alternative antigen-recognition molecules
A

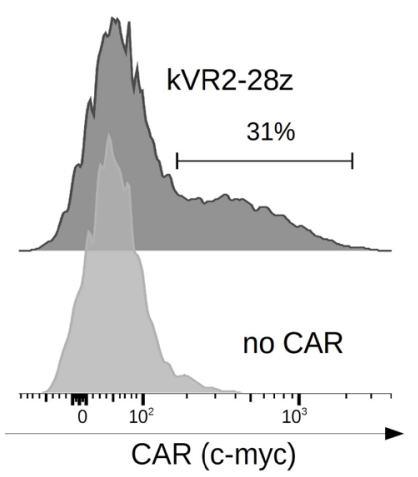

B

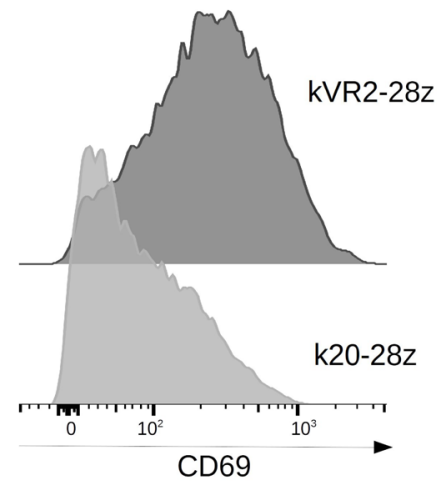

C

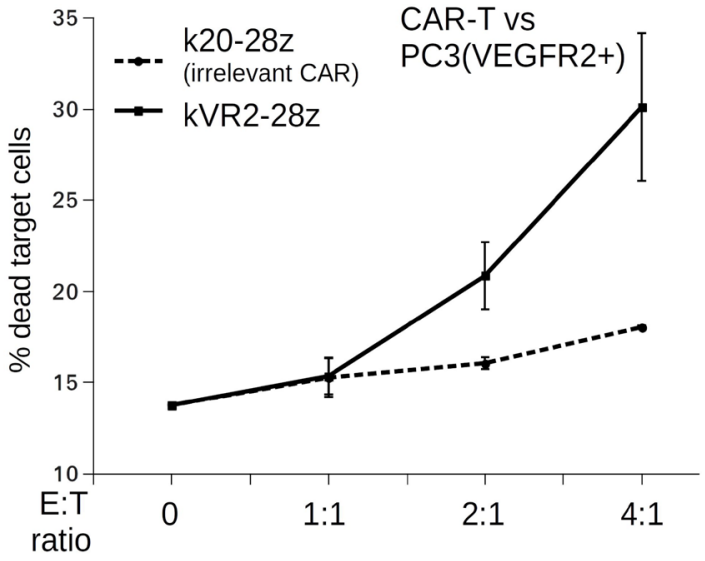

Figure 2: (A) Flow cytometry detection of CAR expression on the surface of transduced FnCAR T cells, as assayed by anti-myc staining. (B) VEGFR2-specific FnCAR-T cells but not irrelevant CAR-T cells (gated by the expression of CAR) become activated (CD69+) upon incubation with target PC3(VEGFR2+) cells. (C) PC3(VEGFR2+) target cell killing by VEGFR2-specific FnCAR-T cells (note that only $\sim 30 \%$ of effector T cell population is FnCAR-positive, (A)), but not by irrelevant CD20-specific k20-28z CAR-T cells.
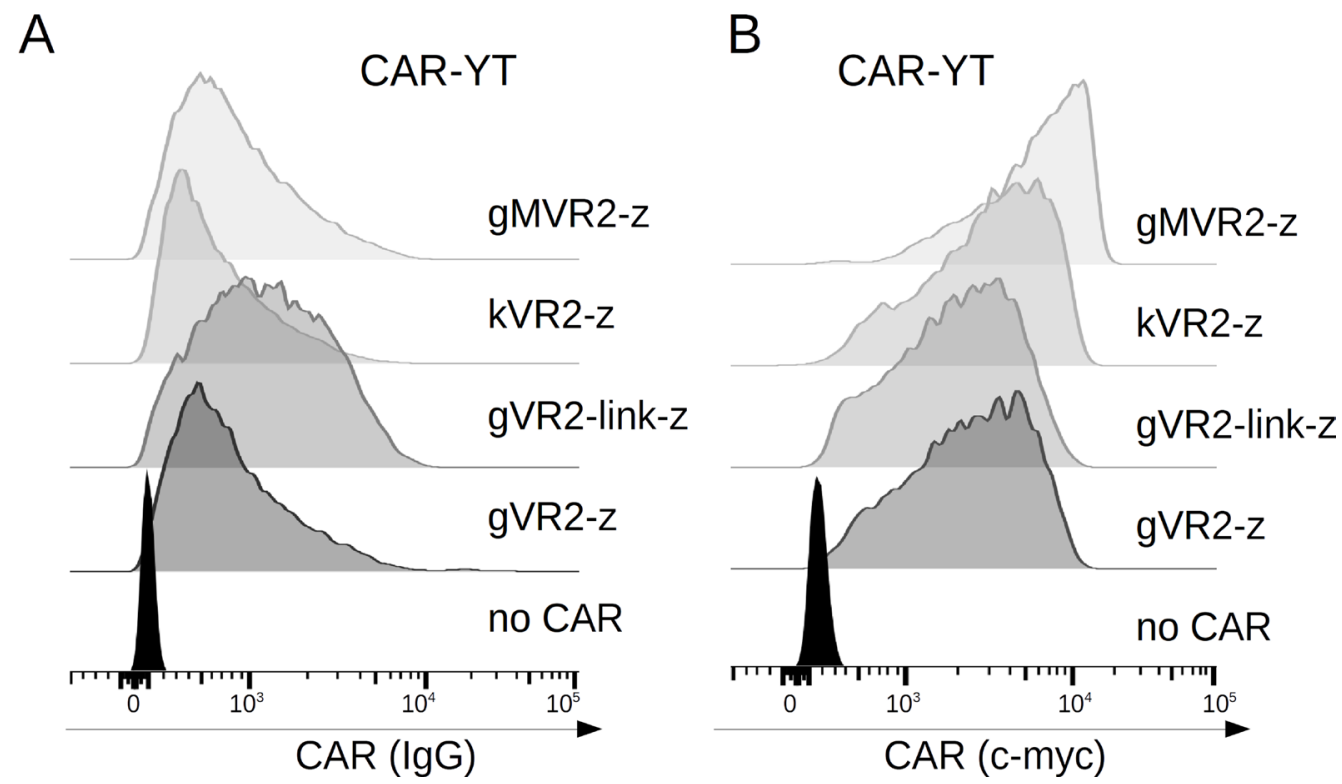

Figure 3: FACS histograms showing CAR expression on the surface of YT cells, as assayed by anti-IgG (A) or anti-myc (B) staining. MFI values (top-down) 1146, 858, 1735, 1278, 148 (A), and 8286, 6465, 5091, 5218,789 (B). 
are of non-human origin, which may limit their successful translation into the clinic due to immunogenicity concerns. The vast majority of the scFv-based CARs tested in clinical trials are murine or humanized. The recent development of fully human scFv-based CARs against several hematological [38-40] and solid [41, 42] cancer cell targets has proven effective in animal models and warrants the exploration of alternative scaffolds based on the human sequences as antigen-recognition modules in CARs. Fn3s represent one such option. These proteins are derived from the $10^{\text {th }}$ type III domain of the human protein fibronectin 1. Fn3s share significant structural homology with variable fragments of antibodies in that they are formed by a sandwich of two antiparallel beta-sheets connected with solvent-accessible CDR-like loops [8, 43]. These loops can be readily diversified and used for the identification of affinity binders to the targets of interest [44]. In contrast to antibody variable fragments, however, Fn3s generally lack intramolecular disulfide bonds or free cysteines. Furthermore, much like VHHs, VLRs, and DARPins, Fn3s are more compact than scFvs and are amenable to tandemization [14]. We envisage that this may help create bi-specific CARs having antigenrecognition modules comprising Fn3s or combinations of Fn3s with scFvs and other scaffolds. Finally, a number of Fn3s developed to date have been shown to bind concave epitopes that are typically inaccessible to bulkier paratopes of scFvs [16]. In our opinion, this feature of Fn3s may translate into a greater choice of epitopes targetable with FnCARs.

In our proof-of-concept study, we asked whether Fn3s can be used as the antigen-recognition modules of CARs and demonstrate that this is indeed the case, consistent with the multitude of non-scFv CARs developed to date. A panel of VEGFR2-specific FnCARs having minor structural differences was successfully designed and expressed in Jurkat, primary T, and YT cells. FnCARs endowed the cells with the ability to become specifically activated when confronted with VEGFR2-positive target cells. In the context of primary human T cells and the YT NK-cell line, FnCAR expression rendered them cytolytic against VEGFR2-expressing targets but not VEGFR2-negative controls, which was accompanied with a significant increase in IFNgamma release. Thus, we demonstrate that FnCARs are fully functional in primary $\mathrm{T}$ cells and YT cells. Finally, recent studies have implicated the framework regions of scFvs as responsible for the effect of ligandindependent tonic signaling in CAR-T cells, which may result in their slow expansion ex vivo, premature exhaustion, and suboptimal persistence once transferred into the patients [7]. We hypothesize that non-scFv formats, such as VHHs, VLRs, DARPins, and Fn3s may help address this problem and afford improved CAR designs.

\section{MATERIALS AND METHODS}

\section{Cell lines and primary $T$ cells}

Jurkat (clone E6-1) cells were purchased from American Type Culture Collection (ATCC), YT cells were kindly provided by Dr. Aleksandr V. Filatov. HEK293T(VEGFR2+) cells were obtained by infecting HEK293T cells with VEGFR2-encoding lentivirus (pCDH-VEGFR2deltaC-IRES-copGFP) followed by
A

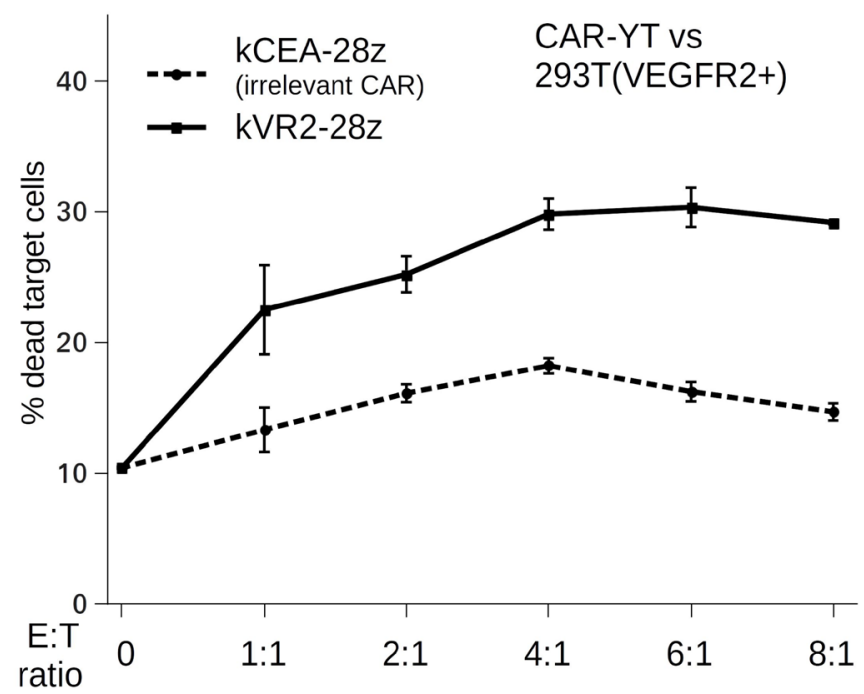

B

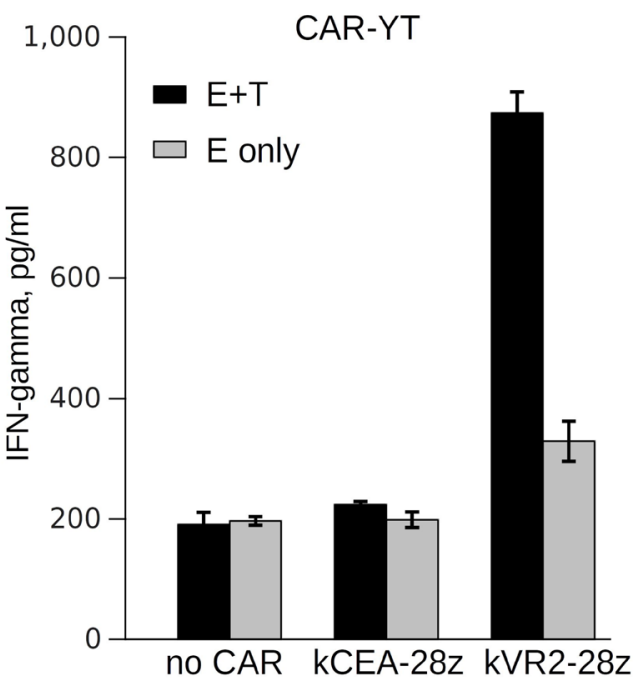

Figure 4: (A) HEK293T(VEGFR2+) target cell killing by VEGFR2-specific FnCAR-YT cells or YT cells transduced with an irrelevant Fn3(CEA)CAR, at the indicated E:T ratios. (B) IFNgamma release by FnCAR-transduced or non-transduced YT cells in the presence (black bars) or absence (grey bars) of target HEK(VEGFR2+) cells. kCEA-28z CAR targeting an irrelevant surface molecule, CEA, was used as a negative control. 
single cell cloning. PC3(VEGFR2+) cells were obtained in a similar way. All of the cell lines were maintained in IMDM supplemented with 10\% FCS (HyClone), $100 \mathrm{U} / \mathrm{ml}$ penicillin, and $100 \mathrm{ug} / \mathrm{ml}$ streptomycin (Sigma).

Primary human PBMCs were isolated from a healthy donor after informed consent in accordance with the Declaration of Helsinki. T cells were purified from PBMCs using Dynabeads Untouched Human T Cells Kit (ThermoFisher) and activated for $24 \mathrm{~h}$ using Human T-activator CD3/CD28 Dynabeads (ThermoFisher). The cells were then kept in a medium supplemented with 50 $\mathrm{U} / \mathrm{ml}$ human IL2 (Peprotech).

\section{Cloning of FnCAR constructs}

Lentiviral vector $\mathrm{pCDH}$ was used as a backbone for the construct design. Based on this vector, first- and second-generation CAR constructs encoding mIgk or Gaussia luciferase signal sequence, myc epitope, hIgG1(hinge-CH2-CH3), CD3z or CD3z+CD28 sequences were obtained (GenBank accession numbers KX757243, KX757244，KX757252，KX757253) [17]. Sequence coding for the Fn3(VEGFR2) module (K10 clone) was extracted from the literature data [13], produced by gene synthesis (Biomatik, Canada) and cloned between unique AgeI and BamHI sites of the above vectors in frame with the rest of the CAR modules. Thus, kVR2-28z, kVR2-z, and gVR2-z constructs were obtained. Next, we explored whether the incorporation of a flexible (GS) ${ }_{11}$ linker would create a more active CAR and whether adding a mycepitope to the N-terminus of Fn3 module would be welltolerated (as recombinant Fn3s have been reported to be sensitive to the changes at their N-termini [13]). A linker sequence was introduced between the Fn3(VEGFR2)- and myc-coding sequences using PCR to form gVR-link-z construct. A duplex of oligos encoding N-myc tag was ligated into the AgeI site of gVR2-z between the Gaussia leader and the Fn3 to obtain gMVR2-z.

\section{Lentivirus production and transduction}

HEK293T cells were co-transfected with FnCARor CAR-encoding lentiviral constructs and packaging plasmids pMD2.G and psPAX2 using the calcium phosphate transfection procedure. Two days later, supernatants were filtered using 0.45 um PES filters. Titers of all viral supernatants were at least $10^{\wedge} 7$ infective particles per ml. Jurkat, primary human T cells or YT cells were transduced with viral supernatants by spinoculation method [45] in the presence of $2 \mathrm{ug} / \mathrm{ml}$ polybrene (Jurkat and YT cells) or $10 \mathrm{ug} / \mathrm{ml}$ protamine sulfate (primary T cells). Jurkat and YT cells were consistently infected at efficiencies above $70 \%$, whereas primary human $\mathrm{T}$ cells were typically transduced at 30-40\% (Figure 2A). Cells infected with different viral samples displayed similar MFI values for copGFP marker, which indicated that a comparable MOI was achieved.

\section{Activation assay}

One hundred thousand FnCAR Jurkat cells were incubated with an equal number of HEK293T(VEGFR2+) or with wild-type HEK293T(VEGFR2-) cells in 24well plates (TPP \# 92124) for $4 \mathrm{~h}$ in a $\mathrm{CO} 2$ incubator. Alternatively, 0.1 million FnCAR-T cells were incubated with an equal number of PC3(VEGFR2+) cells as the targets for $4 \mathrm{~h}$ (irrelevant CD20-specific k20-28z CAR $\mathrm{T}$ cells were used as a negative control). Immediately after incubation, the cells were stained with anti-CD69 antibodies (PE-labeled clone FN50, eBioscience) and analyzed with BD FACSCanto II cytometer.

\section{Fn3 specificity validation and surface CAR expression analysis}

Soluble VEGFR2-specific 2xStrep-2xFLAG-6xHistag labeled Fn3 was produced in E. coli and purified using Ni-NTA agarose (Qiagen) according to the manufacturer's protocol. Briefly, $1 \mathrm{~g}$ of $E$. coli pellet was resuspended in $10 \mathrm{ml}$ of lysis buffer $(20 \mathrm{mM}$ Tris- $\mathrm{HCl} \mathrm{pH} 8.0,350 \mathrm{mM}$ $\mathrm{NaCl}, 20 \mathrm{mM}$ Imidazole, $5 \mathrm{mM}$ beta-ME) and disrupted by French press G-M (Glen Mills). Lysate was clarified by centrifugation and applied to $1 \mathrm{ml}$ of Ni-NTA agarose. The resin was then washed with 5 volumes of lysis buffer and protein was eluted with elution buffer $(20 \mathrm{mM}$ Tris- $\mathrm{HCl}$ pH 8.0, $350 \mathrm{mM} \mathrm{NaCl}, 250 \mathrm{mM}$ Imidazole, $5 \mathrm{mM}$ beta$\mathrm{ME})$. Eluate was dialyzed against PBS and concentrated to $1 \mathrm{mg} / \mathrm{ml}$. HEK293T(VEGFR2+) cells were incubated for $30 \mathrm{~min}$ with $1 \mathrm{ug} / \mathrm{ml}$ of soluble Fn3(VEGFR2) in PBS with $1 \%$ FCS, washed twice with PBS, and stained with anti-FLAG antibodies (clone FG4R, eBioscience). To measure surface CAR expression, either anti-c-myc antibodies (clone 9E10, eBioscience) or anti-IgG-APC conjugates (709-606-098, Jackson ImmunoResearch) were used. Detection of myc- or FLAG-stained cells was performed using PE-anti-mouse IgG conjugates. All FACS gates were set using untransduced cells or cells with an omitted primary antibody.

\section{Cytotoxicity assay and IFNgamma release assay}

For the detection of FnCAR-mediated cell lysis, FACS-based protocol was employed [46]. Briefly, target HEK293T(VEGFR2+) or PC3(VEGFR2+) cells were labelled with Cell Proliferation Dye eFluor ${ }^{\circledR} 670$ (eBioscience), washed, and incubated with Fn3(VEGFR2) CAR-expressing effector cells or control irrelevant CARexpressing cells (T or YT) at various E:T ratios for 4 hours. Then, the cells were stained with 7AAD $(1 \mathrm{ug} / \mathrm{ml})$ and analyzed by flow cytometry. The percentage of dead target cells was calculated as follows: $100 \% *(7 \mathrm{AAD}+, \mathrm{eFluor}+)$ count $/$ (total eFluor +$)_{\text {count }}$.

In order to measure IFNgamma release, Fn3(VEGFR2)CAR YT, irrelevant Fn3(CEA)CAR YT or wild-type YT cells were incubated with target 
HEK293T(VEGFR2+) or control HEK293T(VEGFR2-) cells at a 1:1 ratio for 4 hours. Immediately after incubation, cell culture supernatants were filtered through 0.45 um filters and IFNgamma concentration in the supernatants was measured in duplicates using ELISA (IFA-best kit, Vektor-best, Russia).

\section{Abbreviations}

CAR: chimeric antigen receptor; CDR: complementarity-determining region; CEA: carcinoembryonic antigen (CEACAM5); copGFP: green fluorescent protein 2 from the copepod Pontellina plumata; DARPins: designed ankyrin repeat proteins; Fn3: fibronectin type III domain; FnCAR: Fn3-based chimeric antigen receptor; IRES: internal ribosome entry site; MFI: mean fluorescence intensity; MOI: multiplicity of infection; NK: natural killer; scFv: single-chain fragment variable; VEGFR2: vascular endothelial growth factor receptor 2 (KDR: CD309); VHHs: camelid single-domain antibodies; VLRs: sea lamprey variable lymphocyte receptors.

\section{Author contributions}

S.V.K., A.A.G., and A.V.T. conceived the experiments; S.V.K., A.A.G., A.N.C., V.V.K., O.Y.V., D.A.M. and A.V.P. designed and/or carried out the experiments and analyzed the data; A.Y.Z supervised primary $\mathrm{T}$ cell experiments, and S.V.K. and A.A.G. wrote the article. All authors discussed the results and contributed to the final manuscript.

\section{CONFLICTS OF INTEREST}

No potential conflicts of interest were disclosed.

\section{FUNDING}

This study was supported by the grant \#15-04-05749 (Russian Fund for Basic Research). Work with the YT cell line was made possible by the grant \#16-14-10237 (Russian Science Foundation). A.V.T. was supported by the Fundamental Scientific Research Program (projects 0310-2016-0006 and 0310-2016-0007). The authors gratefully acknowledge the resources provided by the "Molecular and Cellular Biology" core facility of the IMCB SB RAS.

\section{REFERENCES}

1. Kalos M, Levine BL, Porter DL, Katz S, Grupp SA, Bagg A, June CH. T cells with chimeric antigen receptors have potent antitumor effects and can establish memory in patients with advanced leukemia. Sci Transl Med. 2011; 3:95ra73.
2. Kochenderfer JN, Dudley ME, Feldman SA, Wilson WH, Spaner DE, Maric I, Stetler-Stevenson M, Phan GQ, Hughes MS, Sherry RM, Yang JC, Kammula US, Devillier L, et al. B-cell depletion and remissions of malignancy along with cytokine-associated toxicity in a clinical trial of anti-CD19 chimeric-antigen-receptor-transduced T cells. Blood. 2012; 119:2709-2720.

3. Kochenderfer JN, Dudley ME, Kassim SH, Somerville RP, Carpenter RO, Stetler-Stevenson M, Yang JC, Phan GQ, Hughes MS, Sherry RM, Raffeld M, Feldman S, Lu L, et al. Chemotherapy-refractory diffuse large B-cell lymphoma and indolent B-cell malignancies can be effectively treated with autologous $\mathrm{T}$ cells expressing an anti-CD19 chimeric antigen receptor. J Clin Oncol. 2015; 33:540-549.

4. Kochenderfer JN, Wilson WH, Janik JE, Dudley ME, Stetler-Stevenson M, Feldman SA, Maric I, Raffeld M, Nathan DA, Lanier BJ, Morgan RA, Rosenberg SA. Eradication of B-lineage cells and regression of lymphoma in a patient treated with autologous $\mathrm{T}$ cells genetically engineered to recognize CD19. Blood. 2010; 116:4099-4102.

5. Brentjens RJ, Davila ML, Riviere I, Park J, Wang X, Cowell LG, Bartido S, Stefanski J, Taylor C, Olszewska M, Borquez-Ojeda O, Qu J, Wasielewska T, et al. CD19targeted $\mathrm{T}$ cells rapidly induce molecular remissions in adults with chemotherapy-refractory acute lymphoblastic leukemia. Sci Transl Med. 2013; 5:177ra38.

6. Porter DL, Hwang WT, Frey NV, Lacey SF, Shaw PA, Loren AW, Bagg A, Marcucci KT, Shen A, Gonzalez V, Ambrose D, Grupp SA, Chew A, et al. Chimeric antigen receptor $\mathrm{T}$ cells persist and induce sustained remissions in relapsed refractory chronic lymphocytic leukemia. Sci Transl Med. 2015; 7:303ra139.

7. Long AH, Haso WM, Shern JF, Wanhainen KM, Murgai M, Ingaramo M, Smith JP, Walker AJ, Kohler ME, Venkateshwara VR, Kaplan RN, Patterson GH, Fry TJ, et al. 4-1BB costimulation ameliorates $\mathrm{T}$ cell exhaustion induced by tonic signaling of chimeric antigen receptors. Nat Med. 2015; 21:581-590.

8. Main AL, Harvey TS, Baron M, Boyd J, Campbell ID. The three-dimensional structure of the tenth type III module of fibronectin: an insight into RGD-mediated interactions. Cell. 1992; 71:671-678.

9. Koide A, Bailey CW, Huang X, Koide S. The fibronectin type III domain as a scaffold for novel binding proteins. $\mathrm{J}$ Mol Biol. 1998; 284:1141-1151.

10. Koide A, Wojcik J, Gilbreth RN, Hoey RJ, Koide S. Teaching an old scaffold new tricks: monobodies constructed using alternative surfaces of the FN3 scaffold. J Mol Biol. 2012; 415:393-405.

11. Koide S, Koide A, Lipovsek D. Target-binding proteins based on the 10th human fibronectin type III domain ((1) (0)Fn3). Methods Enzymol. 2012; 503:135-156.

12. Natarajan A, Hackel BJ, Gambhir SS. A novel engineered anti-CD20 tracer enables early time PET imaging in a 
humanized transgenic mouse model of B-cell non-Hodgkins lymphoma. Clin Cancer Res. 2013; 19:6820-6829.

13. Getmanova EV, Chen Y, Bloom L, Gokemeijer J, Shamah S, Warikoo V, Wang J, Ling V, Sun L. Antagonists to human and mouse vascular endothelial growth factor receptor 2 generated by directed protein evolution in vitro. Chem Biol. 2006; 13:549-556.

14. Emanuel SL, Engle LJ, Chao G, Zhu RR, Cao C, Lin Z, Yamniuk AP, Hosbach J, Brown J, Fitzpatrick E, Gokemeijer J, Morin P, Morse BA, et al. A fibronectin scaffold approach to bispecific inhibitors of epidermal growth factor receptor and insulin-like growth factor-I receptor. MAbs. 2011; 3:38-48.

15. Pirie CM, Hackel BJ, Rosenblum MG, Wittrup KD. Convergent potency of internalized gelonin immunotoxins across varied cell lines, antigens, and targeting moieties. J Biol Chem. 2011; 286:4165-4172.

16. Ramamurthy V, Krystek SR Jr, Bush A, Wei A, Emanuel SL, Das Gupta R, Janjua A, Cheng L, Murdock M, Abramczyk B, Cohen D, Lin Z, Morin P, et al. Structures of adnectin/protein complexes reveal an expanded binding footprint. Structure. 2012; 20:259-269.

17. Kulemzin SV, Chikaev NA, Volkova OY, Kuznetsova VV, Taranin AV, Gorchakov AA. Modular lentiviral vectory system for optimization of chimeric antigen receptor design. Russ J Bioorganic Chem. 2017; 43:1-9.

18. Suck G, Odendahl M, Nowakowska P, Seidl C, Wels WS, Klingemann HG, Tonn T. NK-92: an 'off-the-shelf therapeutic' for adoptive natural killer cell-based cancer immunotherapy. Cancer Immunol Immunother. 2016; 65:485-492.

19. Yodoi J, Teshigawara K, Nikaido T, Fukui K, Noma T, Honjo T, Takigawa M, Sasaki M, Minato N, Tsudo M. TCGF (IL 2)-receptor inducing factor(s). I. Regulation of IL 2 receptor on a natural killer-like cell line (YT cells). J Immunol. 1985; 134:1623-1630.

20. Fedorov VD, Themeli M, Sadelain M. PD-1- and CTLA-4based inhibitory chimeric antigen receptors (iCARs) divert off-target immunotherapy responses. Sci Transl Med. 2013; 5:215ra172.

21. Roybal KT, Rupp LJ, Morsut L, Walker WJ, McNally KA, Park JS, Lim WA. Precision Tumor Recognition by T Cells With Combinatorial Antigen-Sensing Circuits. Cell. 2016; 164:770-779.

22. Wilkie S, van Schalkwyk MC, Hobbs S, Davies DM, van der Stegen SJ, Pereira AC, Burbridge SE, Box C, Eccles SA, Maher J. Dual targeting of ErbB2 and MUC1 in breast cancer using chimeric antigen receptors engineered to provide complementary signaling. J Clin Immunol. 2012; 32:1059-1070.

23. Kloss CC, Condomines M, Cartellieri M, Bachmann M, Sadelain M. Combinatorial antigen recognition with balanced signaling promotes selective tumor eradication by engineered T cells. Nat Biotechnol. 2013; 31:71-75.
24. Lanitis E, Poussin M, Klattenhoff AW, Song D, Sandaltzopoulos R, June CH, Powell DJ Jr. Chimeric antigen receptor $\mathrm{T}$ cells with dissociated signaling domains exhibit focused antitumor activity with reduced potential for toxicity in vivo. Cancer Immunol Res. 2013; 1:43-53.

25. Morsut L, Roybal KT, Xiong X, Gordley RM, Coyle SM, Thomson M, Lim WA. Engineering customized cell sensing and response behaviors using synthetic Notch receptors. Cell. 2016; 164:780-791.

26. Zah E, Lin MY, Silva-Benedict A, Jensen MC, Chen YY. T cells expressing CD19/CD20 bispecific chimeric antigen receptors prevent antigen escape by malignant $\mathrm{B}$ cells. Cancer Immunol Res. 2016; 4:498-508.

27. Hegde M, Mukherjee M, Grada Z, Pignata A, Landi D, Navai SA, Wakefield A, Fousek K, Bielamowicz K, Chow KK, Brawley VS, Byrd TT, Krebs S, et al. Tandem CAR T cells targeting HER2 and IL13Ralpha2 mitigate tumor antigen escape. J Clin Invest. 2016; 126:3036-3052.

28. Grada Z, Hegde M, Byrd T, Shaffer DR, Ghazi A, Brawley VS, Corder A, Schonfeld K, Koch J, Dotti G, Heslop HE, Gottschalk S, Wels WS, et al. TanCAR: A novel bispecific Chimeric Antigen Receptor for cancer immunotherapy. Mol Ther Nucleic Acids. 2013; 2:e105.

29. Jamnani FR, Rahbarizadeh F, Shokrgozar MA, Mahboudi F, Ahmadvand D, Sharifzadeh Z, Parhamifar L, Moghimi SM. $\mathrm{T}$ cells expressing VHH-directed oligoclonal chimeric HER2 antigen receptors: towards tumor-directed oligoclonal T cell therapy. Biochim Biophys Acta. 2014; 1840:378-86.

30. Sharifzadeh Z, Rahbarizadeh F, Shokrgozar MA, Ahmadvand D, Mahboudi F, Jamnani FR, Moghimi SM. Genetically engineered $\mathrm{T}$ cells bearing chimeric nanoconstructed receptors harboring TAG-72-specific camelid single domain antibodies as targeting agents. Cancer Lett. 2013; 334:237-244.

31. Zhang G, Liu R, Zhu X, Wang L, Ma J, Han H, Wang X, Zhang G, He W, Wang W, Liu C, Li S, Sun M, et al. Retargeting NK-92 for anti-melanoma activity by a TCRlike single-domain antibody. Immunol Cell Biol. 2013; 91:615-624.

32. Zhang G, Wang L, Cui H, Wang X, Zhang G, Ma J, Han H, He W, Wang W, Zhao Y, Liu C, Sun M, Gao B. Antimelanoma activity of $\mathrm{T}$ cells redirected with a TCR-like chimeric antigen receptor. Sci Rep. 2014; 4:3571.

33. Moot R, Raikar SS, Fleischer L, Querrey M, Tylawsky DE, Nakahara H, Doering CB, Spencer HT. Genetic engineering of chimeric antigen receptors using lamprey derived variable lymphocyte receptors. Mol Ther Oncolytics. 2016; 3:16026.

34. Hammill JA, VanSeggelen H, Helsen CW, Denisova GF, Evelegh C, Tantalo DG, Bassett JD, Bramson JL. Designed ankyrin repeat proteins are effective targeting elements for chimeric antigen receptors. J Immunother Cancer. 2015; 3:55.

35. Davies DM, Foster J, Van Der Stegen SJ, ParentePereira AC, Chiapero-Stanke L, Delinassios GJ, 
Burbridge SE, Kao V, Liu Z, Bosshard-Carter L, Van Schalkwyk MC, Box C, Eccles SA, et al. Flexible targeting of ErbB dimers that drive tumorigenesis by using genetically engineered T cells. Mol Med. 2012; 18:565-576.

36. Pameijer CR, Navanjo A, Meechoovet B, Wagner JR, Aguilar B, Wright CL, Chang WC, Brown CE, Jensen MC. Conversion of a tumor-binding peptide identified by phage display to a functional chimeric $\mathrm{T}$ cell antigen receptor. Cancer Gene Ther. 2007; 14:91-97.

37. Huang G, Yu L, Cooper LJ, Hollomon M, Huls H, Kleinerman ES. Genetically modified T cells targeting interleukin-11 receptor alpha-chain kill human osteosarcoma cells and induce the regression of established osteosarcoma lung metastases. Cancer Res. 2012; 72:271-281.

38. Sommermeyer D, Hill T, Shamah SM, Salter AI, Chen Y, Mohler KM, Riddell SR. Fully human CD19-specific chimeric antigen receptors for T-cell therapy. Leukemia. 2017; 31:2191-2199.

39. Haso W, Lee DW, Shah NN, Stetler-Stevenson M, Yuan CM, Pastan IH, Dimitrov DS, Morgan RA, FitzGerald DJ, Barrett DM, Wayne AS, Mackall CL, Orentas RJ. Anti-CD22-chimeric antigen receptors targeting B-cell precursor acute lymphoblastic leukemia. Blood. 2013; 121:1165-1174.

40. Adams GB, Feng J, Ghogha A, Mardiros A, Murakami J, Phung T, Rodriguez R, Sievers S, Spindler TJ, Wiltzius J, Yarka C, Yoder SC, Polverino T. Abstract 4979:
Development of KITE-585: A fully human BCMA CAR T-cell therapy for the treatment of multiple myeloma. Cancer Res. 2017; 77:4979.

41. Lanitis E, Poussin M, Hagemann IS, Coukos G, Sandaltzopoulos R, Scholler N, Powell DJ Jr. Redirected antitumor activity of primary human lymphocytes transduced with a fully human anti-mesothelin chimeric receptor. Mol Ther. 2012; 20:633-643.

42. Song DG, Ye Q, Poussin M, Liu L, Figini M, Powell DJ Jr. A fully human chimeric antigen receptor with potent activity against cancer cells but reduced risk for off-tumor toxicity. Oncotarget. 2015; 6:21533-21546. https://doi. org/10.18632/oncotarget.4071.

43. Dickinson CD, Gay DA, Parello J, Ruoslahti E, Ely KR. Crystals of the cell-binding module of fibronectin obtained from a series of recombinant fragments differing in length. J Mol Biol. 1994; 238:123-127.

44. Bloom L, Calabro V. FN3: a new protein scaffold reaches the clinic. Drug Discov Today. 2009; 14:949-955.

45. O'Doherty U, Swiggard WJ, Malim MH. Human immunodeficiency virus type 1 spinoculation enhances infection through virus binding. J Virol. 2000; 74:10074-10080.

46. Kim GG, Donnenberg VS, Donnenberg AD, Gooding W, Whiteside TL. A novel multiparametric flow cytometrybased cytotoxicity assay simultaneously immunophenotypes effector cells: comparisons to a $4 \mathrm{~h} 51 \mathrm{Cr}$-release assay. J Immunol Methods. 2007; 325:51-66. 